\title{
Behaviour of masonry structures during the Bhuj earthquake of January 2001
}

\author{
K S Jagadish ${ }^{1}$, S Raghunath ${ }^{2}$ and K S Nanjunda RaO ${ }^{3}$ \\ ${ }^{1}$ Professor, Department of Civil Engineering, Indian Institute of Science, Bangalore 560 012, India \\ ${ }^{2}$ Lecturer, Department of Civil Engineering, B.M.S College of Engineering, Bangalore 560 019, India \\ ${ }^{3}$ Senior Scientific Officer, Department of Civil Engineering, Indian Institute of Science, Bangalore 560 012, India
}

\begin{abstract}
A variety of masonry structures suffered damage during the recent Bhuj earthquake. Some of the traditional masonry structures had no earthquake resistant features and suffered considerable damage. This paper attempts to evaluate the behaviour of masonry structures based on the type of masonry used in places like Bhuj, Anjar, Bhachau, Morbi, Samakhyali and several other places. Quite a few masonry buildings had used earthquake resistant features like lintel bands and corner reinforcements. The cracking and failure patterns of such buildings have also been examined. The paper concludes with a discussion on the relevance of the current codal provisions for earthquake resistance of masonry structures and the direction of further research in the area.
\end{abstract}

\section{Introduction}

Unreinforced masonry structures are the most vulnerable during an earthquake. Normally they are designed for vertical loads and since masonry has adequate compressive strength, the structures behave well as long as the loads are vertical. When such a masonry structure is subjected to lateral inertial loads during an earthquake, the walls develop shear and flexural stresses. The strength of masonry under these conditions often depends on the bond between brick and mortar (or stone and mortar), which is quite poor. This bond is also often very poor when lime mortars or mud mortars are used. A masonry wall can also undergo in-plane shear stresses if the inertial forces are in the plane of the wall. Shear failure in the form of diagonal cracks is observed due to this. However, catastrophic collapses take place when the wall experiences out-of-plane flexure. This can bring down a roof and cause more damage. Masonry buildings with light roofs such as tiled roofs are more vulnerable to out-of-plane vibrations since the top edge can undergo large deformations.
It is always useful to investigate the behaviour of masonry buildings after an earthquake, so as to identify any inadequacies in earthquake resistant design. Studying types of masonry construction, their performance and failure patterns helps in improving the design and detailing aspects.

After the Bhuj earthquake that rocked the state of Gujarat on the 26th January 2001, causing large scale destruction in the Kachchh and surrounding region the authors visited the affected areas thrice to study the damages to buildings.

\section{Masonry structures studied}

The following paragraphs give the description of the behaviour of masonry buildings in some of the places visited.

The old buildings in the town of Morbi were essentially made of well-cut sandstone units in lime mortar. All such buildings have responded badly whereas, neighbouring brick-incement-mortar buildings survived although they developed extensive cracks. The failure pattern may be essentially characterized as out-ofplane failure due to the extremely low value

Keywords. Masonry; out-of-plane failure; earthquake resistance; ductility; containment reinforcement. 


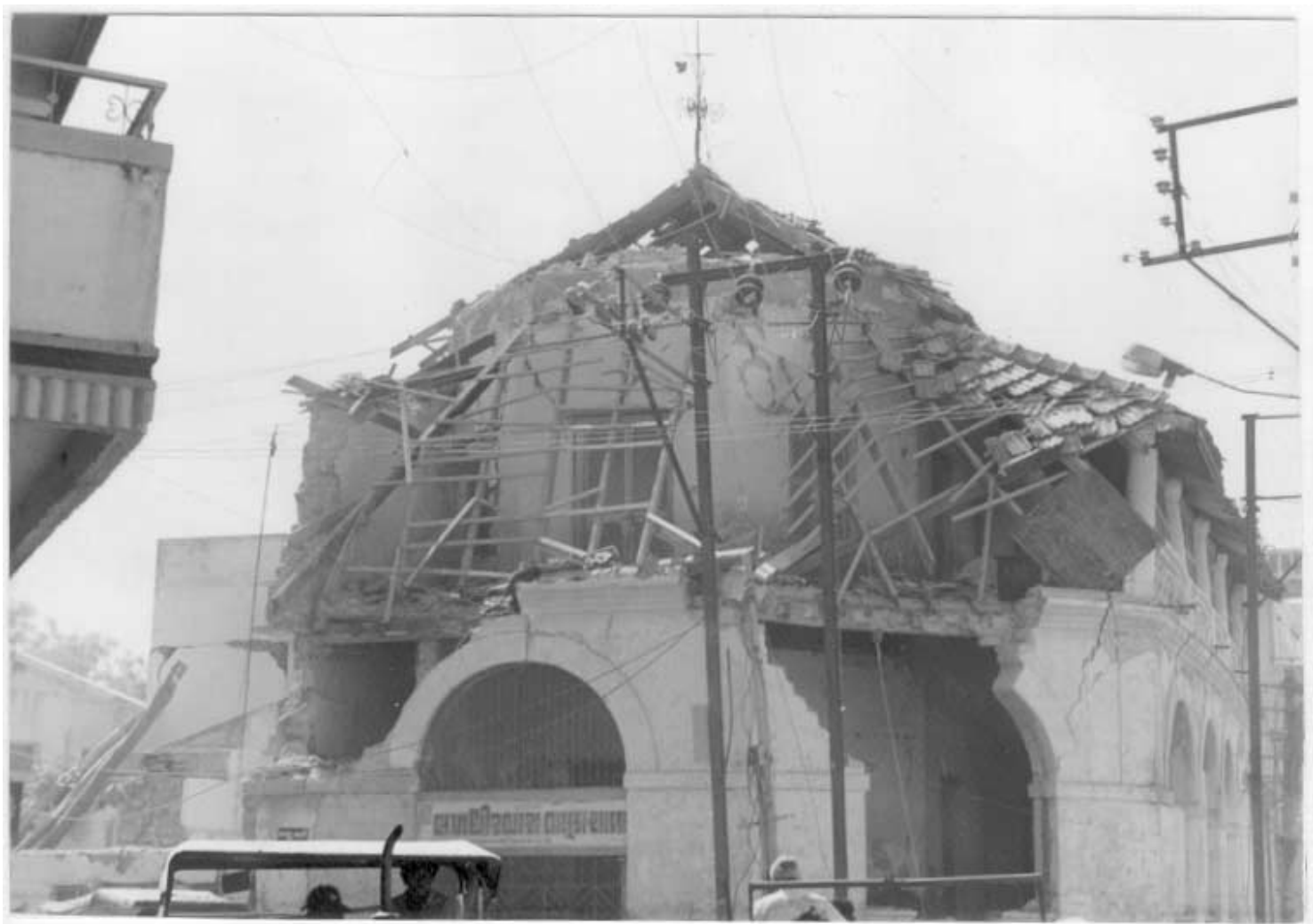

Figure 1. Out-of-plane collapse (Morbi).

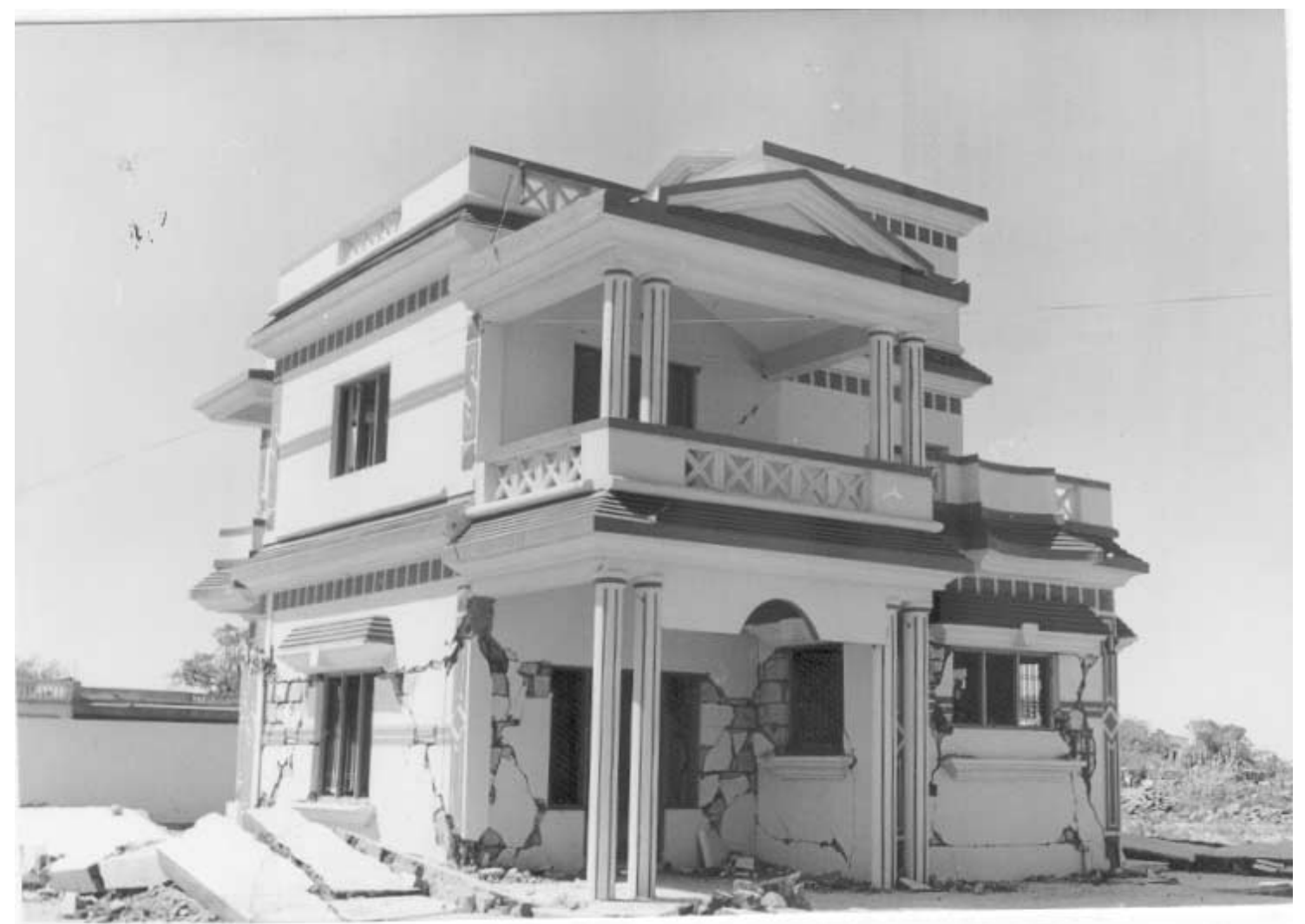

Figure 2. House with lintel band and corner columns, cracks below band (Samakhyali). 


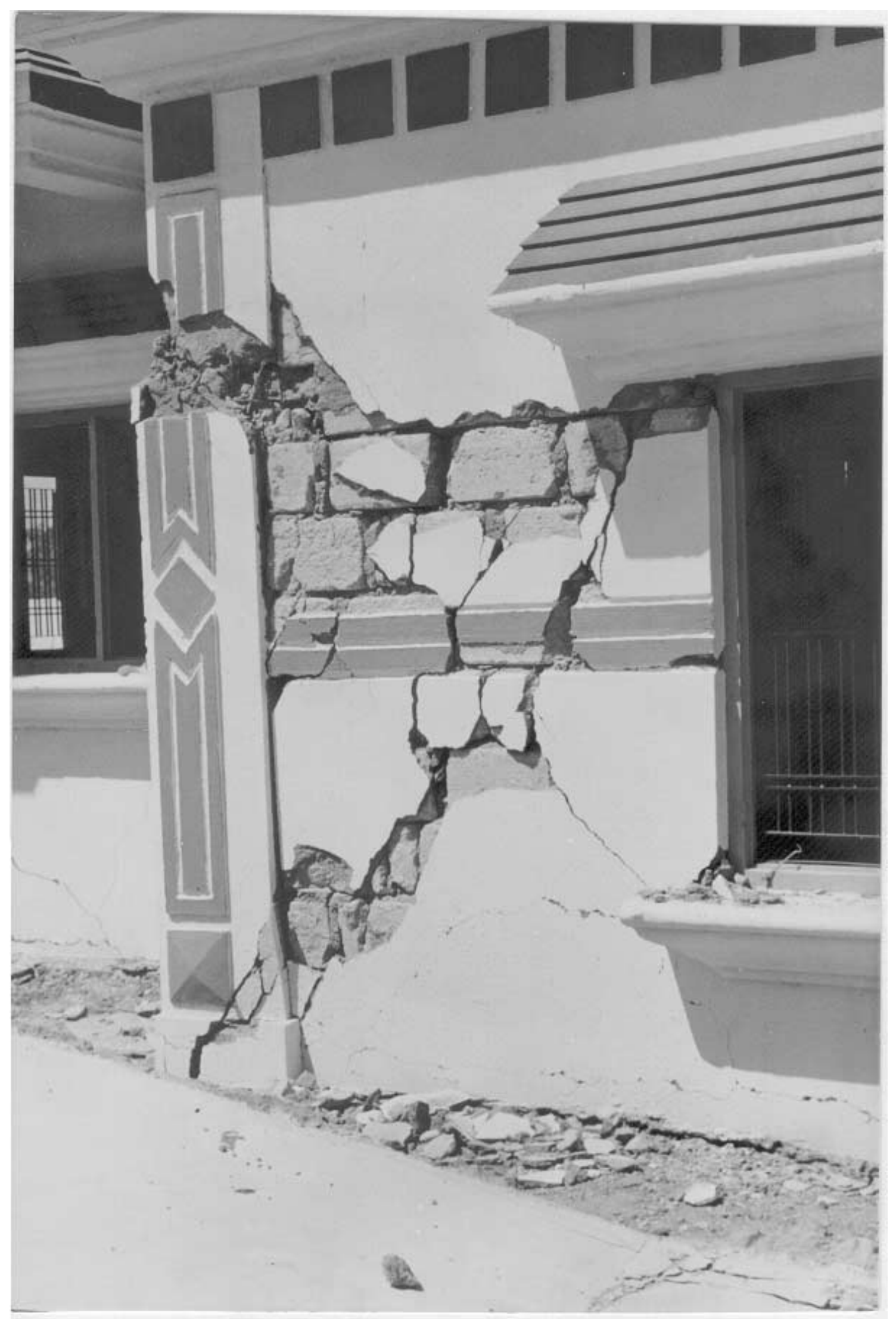

Figure 3. Wall separated from column (Samakhyali). 


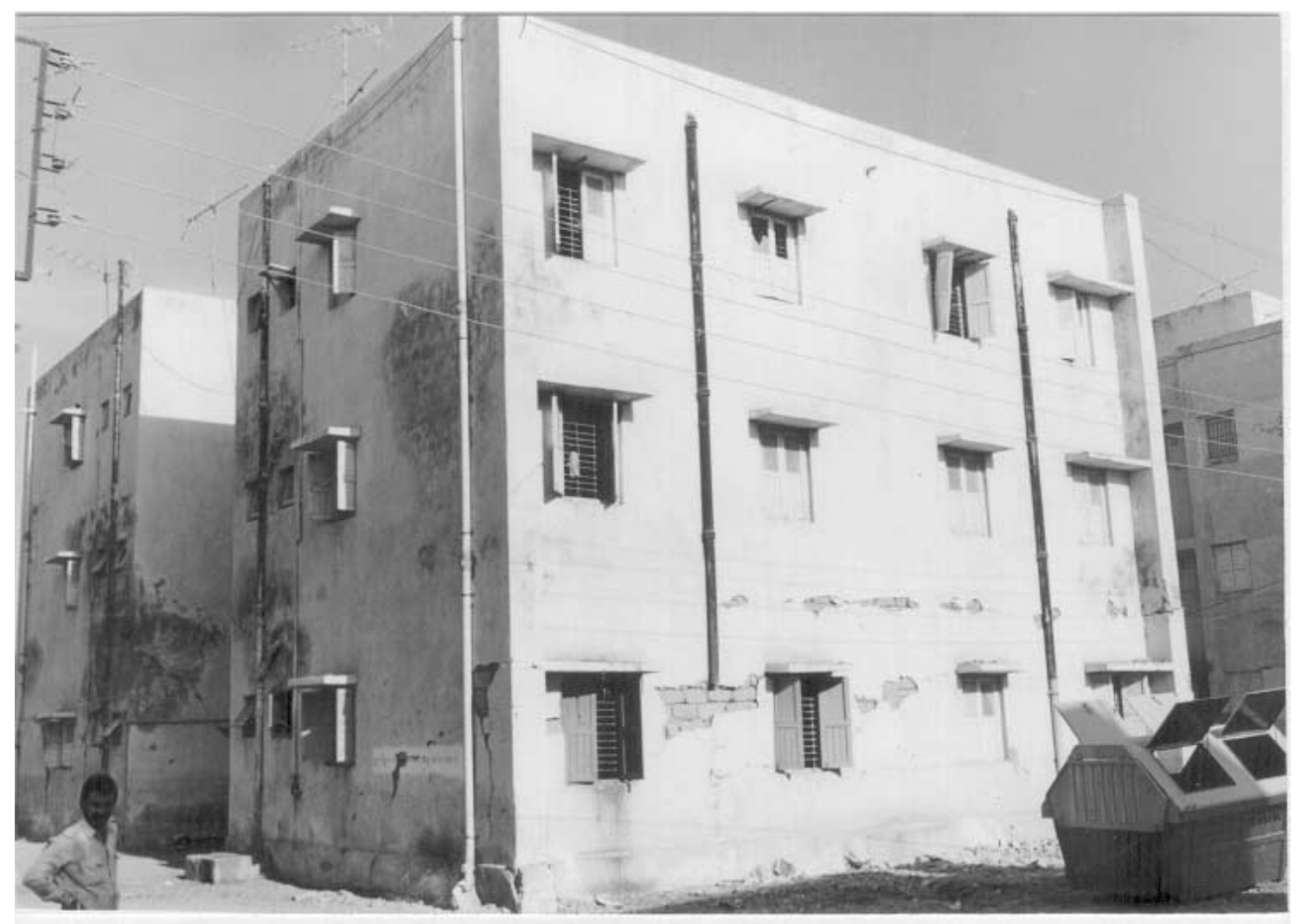

Figure 4. Stone masonry building in CM with minor damage (Bhuj).

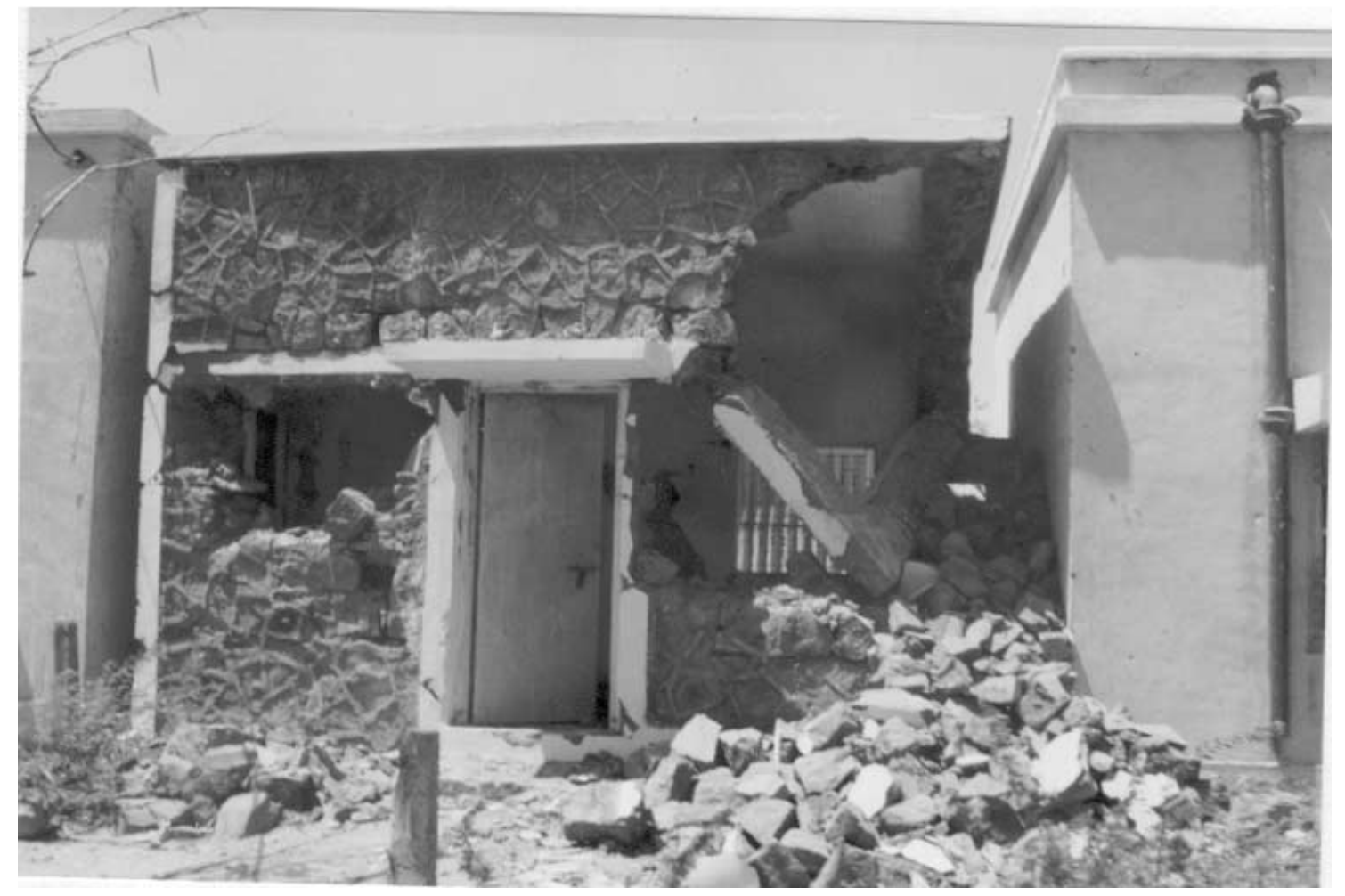

Figure 5. Out-of-plane failure of wall leading to collapse of lintel band (Bhuj). 


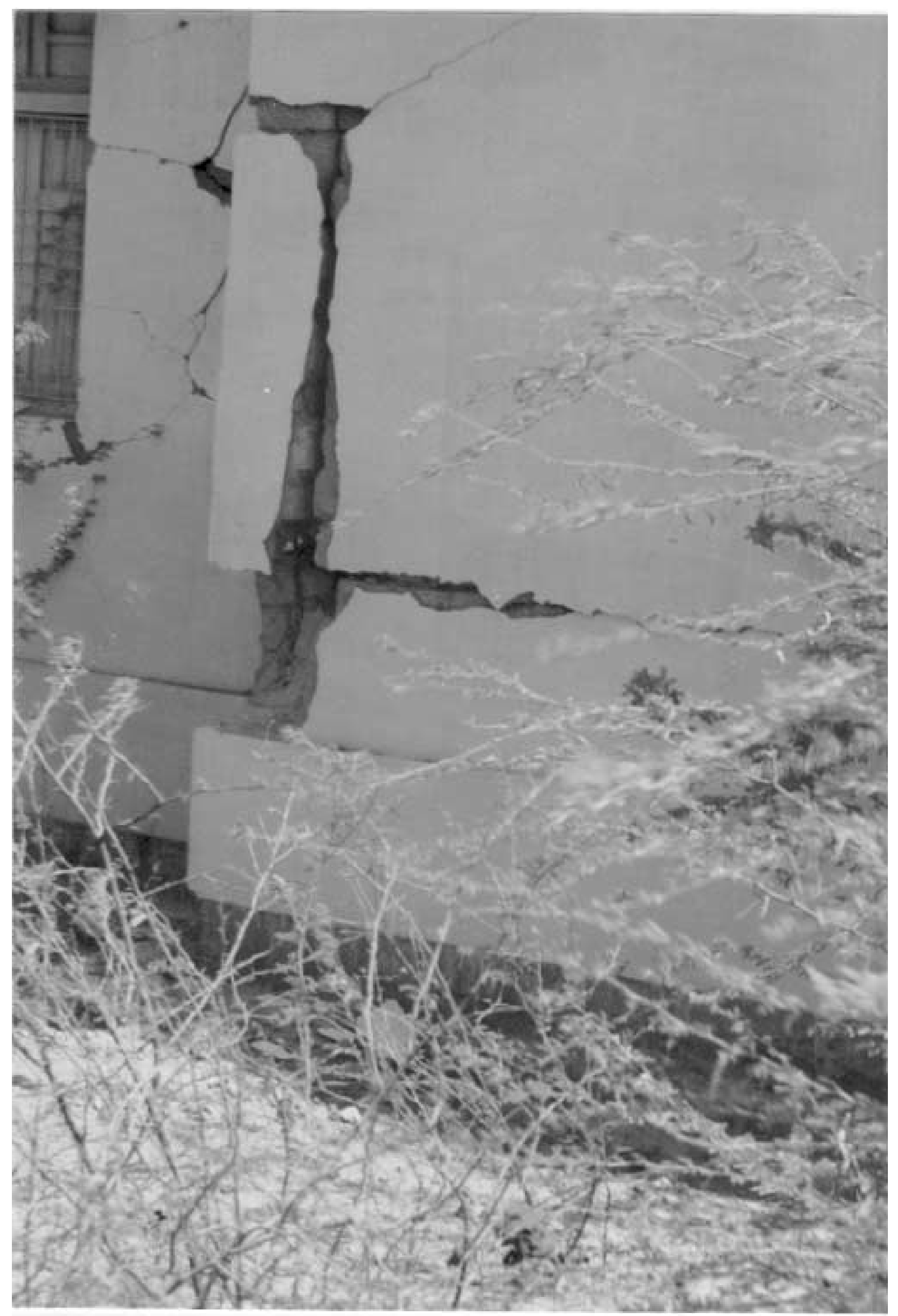

Figure 6. Corner failure in the presence of corner reinforcement (Bhuj). 


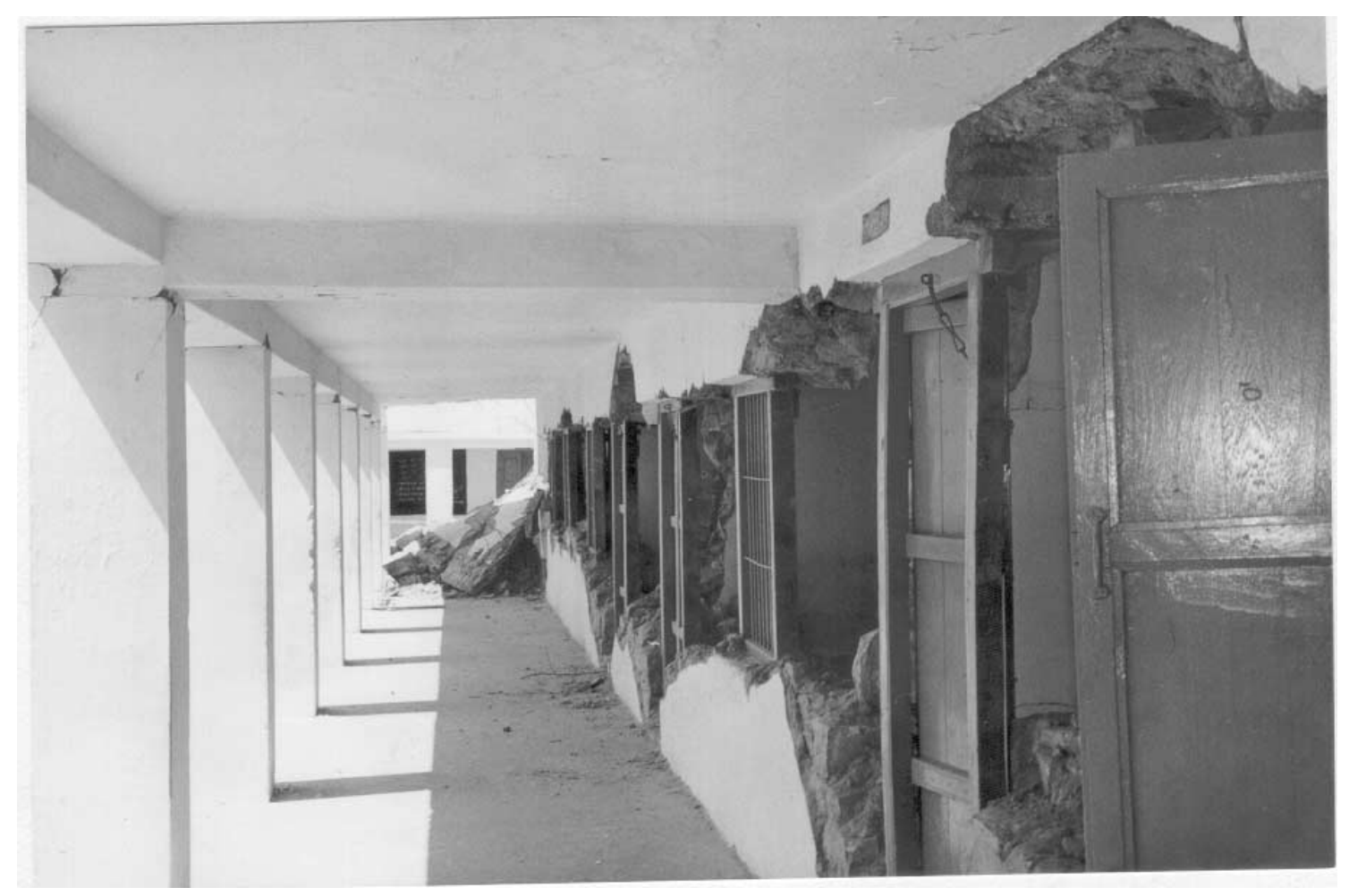

Figure 7. Collapse of wall between openings (Khavda).

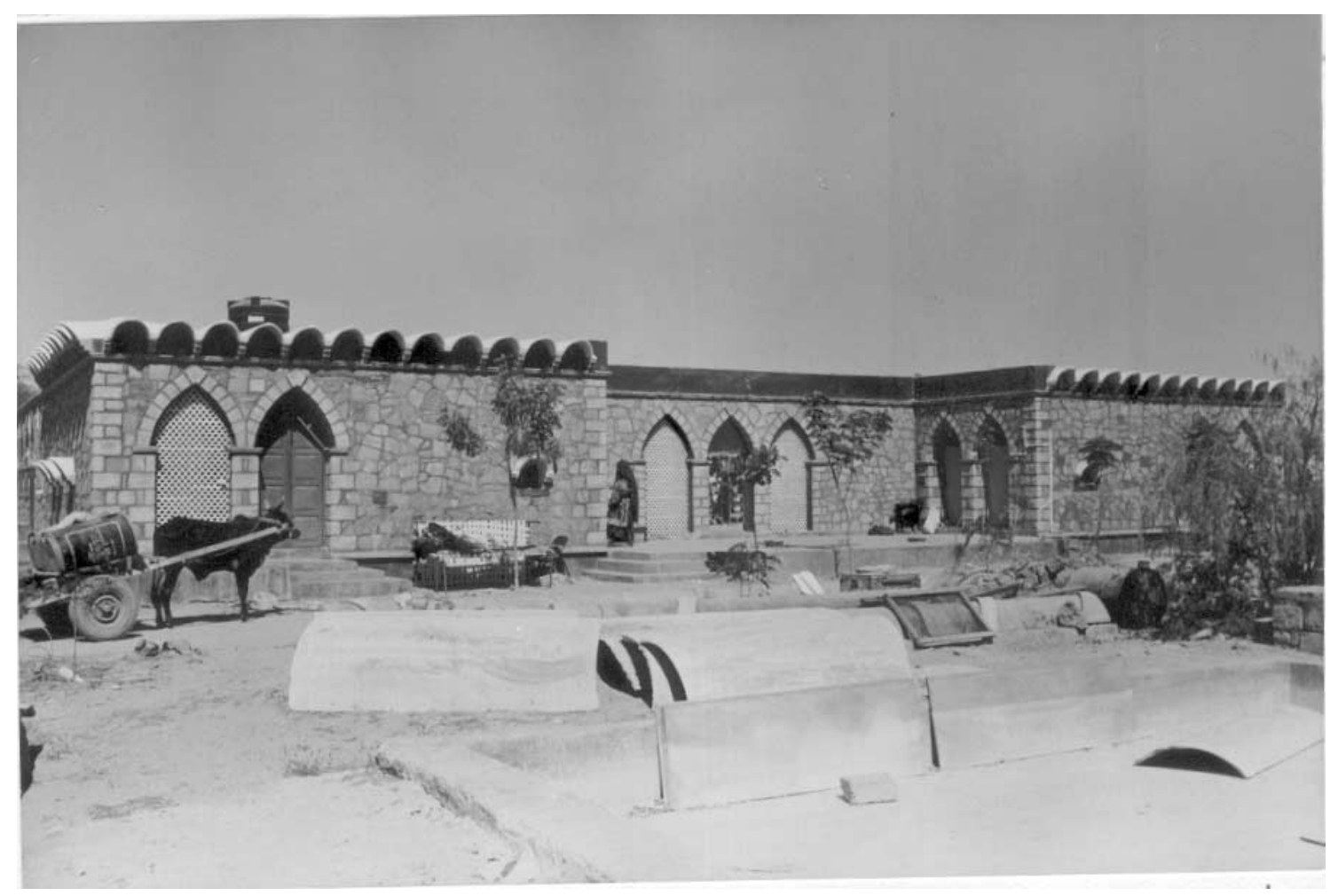

Figure 8. Well dressed stone in CM with ferrocement roof (Khavda). 


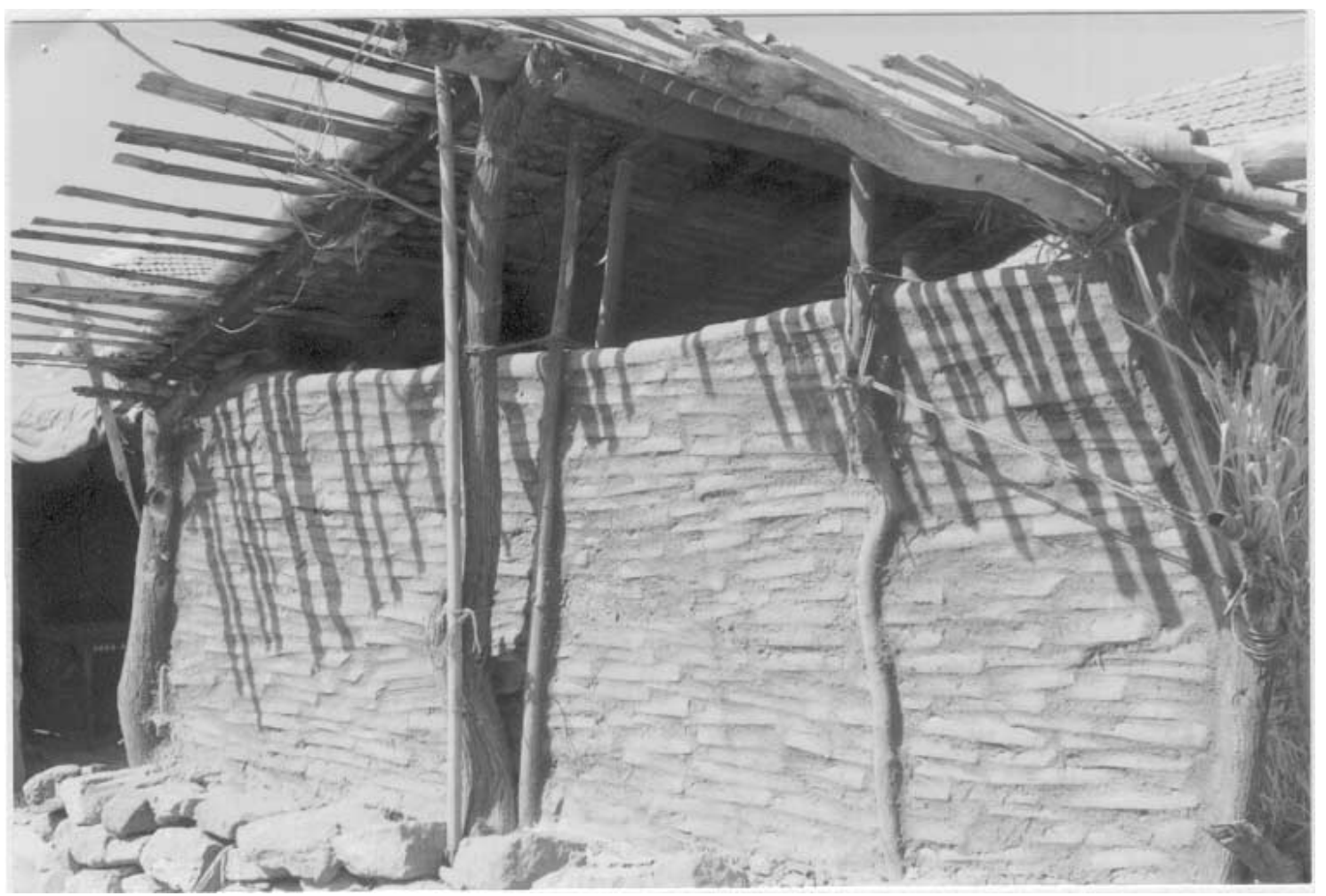

Figure 9. 'Naliyawali Deewal' (Jhadawas, Rapar taluk).

of flexural strength. Figure 1 shows one such typical failure. Out-of-plane failure of parapet walls, failure of stair case blocks was also quite common.

In Samakhyali, the behaviour of an interesting two storeyed building with earthquake resistant features could be observed (figure 2). This building was constructed using cement blocks, with continuous lintel band and corner RC columns. This building did not collapse, but had developed extensive cracks below the lintel band. The portion of the building above the lintel band was practically crack-free. The corner columns suffered severe damage. It appears as though the portion below the lintel band behaved like a 'soft first storey', absorbing all the energy. It is indeed clear that the lintel band protected the portion above by creating a rigid block. The damage below the lintel band may indicate the need for horizontal band, possibly at sill level. The provision of the RC column at the corners or elsewhere, without bonding with the infill walls is not helpful as it causes a discontinuity in masonry walls leading to the building losing its integrity (figure 3 ).

The old Anjar town, with a number of stone-in-mud masonry buildings, was completely devastated. The recent buildings using brickin-cement-mortar showed a much better beha- viour. The vulnerability of out-of-plane collapse of masonry walls could be discerned by the large amount of debris in the narrow lanes.

The damage at Bachau was indeed on an unprecedented scale. The entire town was practically razed to the ground. Total failure of stonein-mud masonry buildings was seen. A couple of two-storeyed masonry buildings with lintel bands and corner columns had behaved similarly to the buildings in Samakhyali, the portion above the lintel band being almost intact.

The structures in the old town of Bhuj, within the fort premises, were devastated. There were many one- and two-storeyed stone-in-mud type buildings with poor bonding, of which none had survived. However, in the new Bhuj town, most of the one- or two-storeyed buildings using brick/stone in cement mortar behaved reasonably well with minor cracks. Figure 4 shows a threestoreyed stone masonry building with cement mortar, which had performed rather well, while a near-by framed RC structure, had collapsed. Some of the masonry buildings built by the CPWD had earthquake resistant features like lintel band and corner reinforcement. Two such buildings were studied. In one building the wall below the lintel band suffered out-of-plane failure and the lintel band also had come down (figure 5). In another 


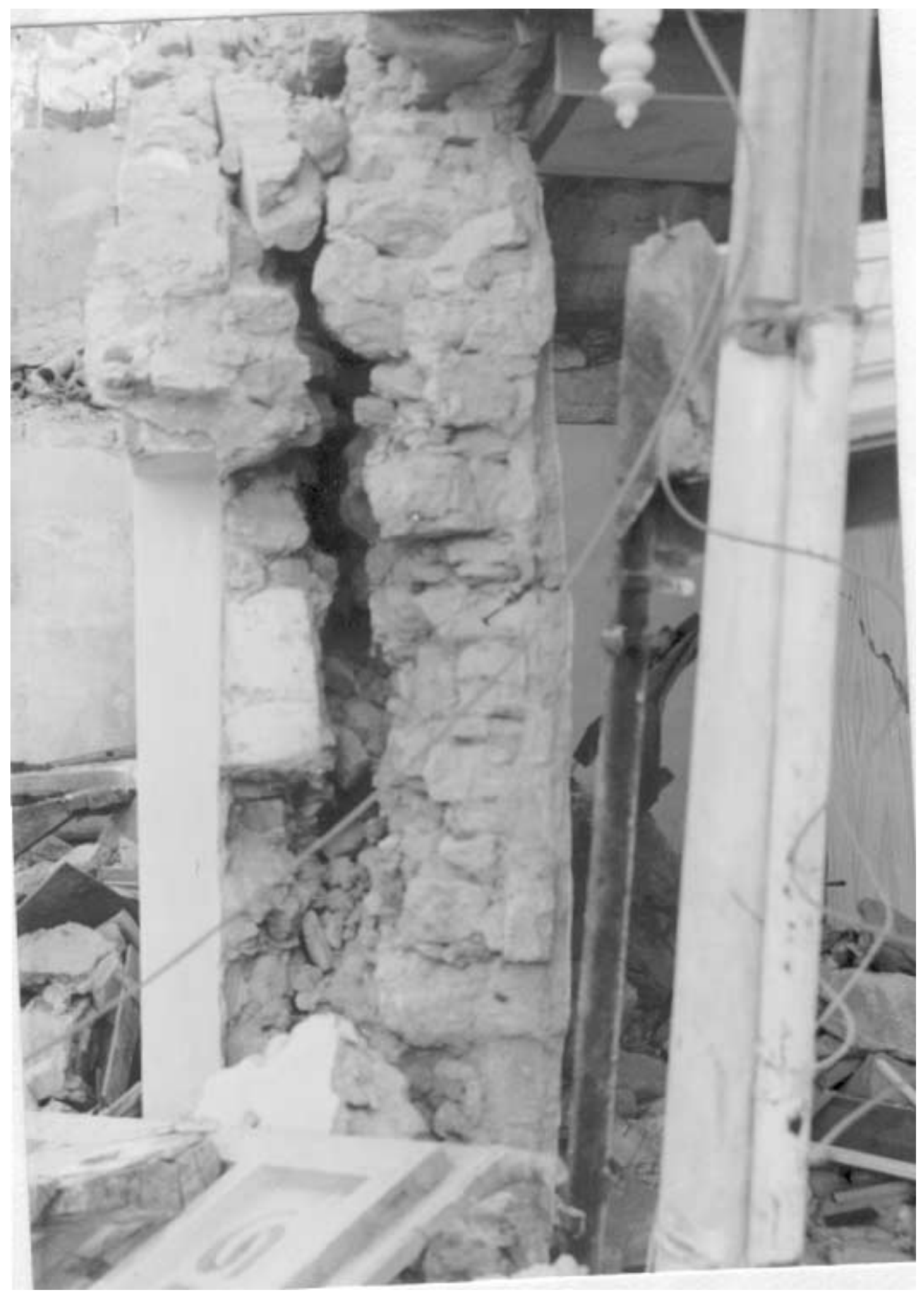

Figure 10. Delaminated wall with buckled wythes (Anjar).

building, the corners were badly fractured and the stones came out inspite of the corner reinforcement. The provision of the corner reinforcement is not possible without having a continuous vertical joint, whereas, masonry demands that continuous vertical joints be avoided. These buildings indicate the inadequacy of such measures when the ground motion intensity is high (figure 6). 


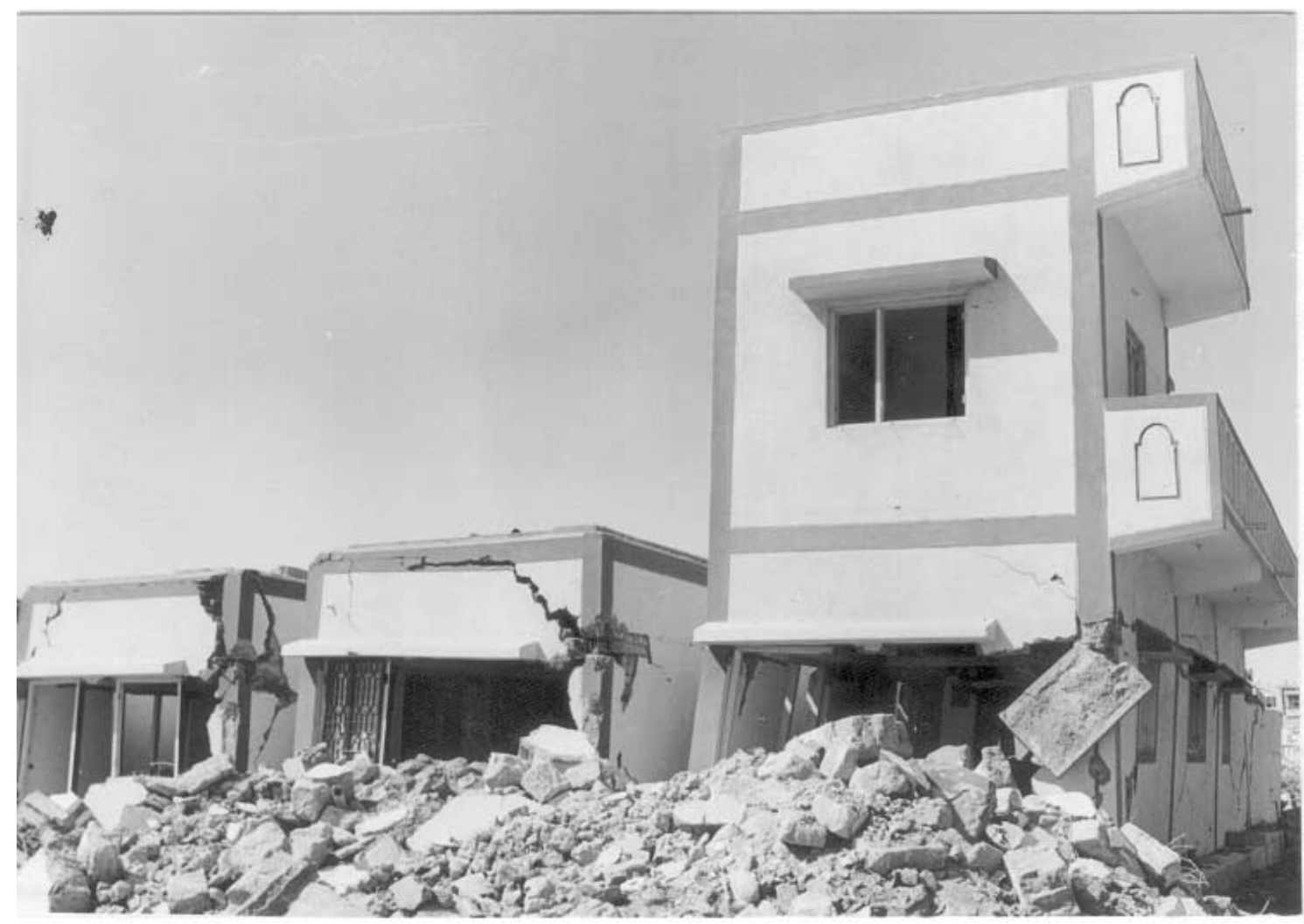

Figure 11. Rigid box-like behaviour above lintel band (Bachau).

Figure 7 shows a school building in Khavda, with typical out-of-plane failure of walls between two openings. Studies (Satish Kumar 1999) have shown that the strip of wall between two large openings experiences large deformations during flexural vibrations. A well dressed stone masonry building, for Kutch Navnirman Abhiyan, with cement mortar and light ferrocement roofing behaved well with very little cracking (figure 8).

In the village of Jhadawas, an interesting structure with a very thin wall of about $12 \mathrm{cms}$ thickness, locally called as 'Naliyawali Deewal' made out of country tiles was prevented from collapse by thin sticks on either face of the wall, held together by coir ropes. Figure 9 shows the details of the wall.

\section{Summary of observations}

Based on the observations of the damages caused to a variety of masonry structures during the Bhuj earthquake the following conclusions could be drawn:

- Masonry buildings in mud mortar or lime mortar are prone to severe damage due to lack of bond strength. Use of rounded stones in wythes without through-stones can further aggravate the problem. The failures of such structures are essentially due to out-of-plane flexure (figure 10).
- Masonry with cement mortar (which has higher bond strength) has generally behaved better, although it does not mean that good masonry bonding is all that is needed for earthquake resistance.

- Use of lintel band, as suggested by the Bureau of Indian Standards (IS 13828:1993), appears to introduce a rigid box-like behaviour in the upper portions of the building while the portion below the lintel band is cracked badly (figure 11). This horizontal reinforcement in the band does not seem to improve the ductility to the desired level. This seems to suggest that additional horizontal bands, possibly at the sill level and at plinth level, are needed.

- The provision of corner reinforcement in corners and junctions, again as suggested by BIS, has to be properly bonded with the surrounding masonry possibly with dowels or keys to prevent separation.

\section{Some suggestions for earthquake resistant masonry}

Since the brittle nature of masonry buildings is the major cause for collapse of buildings and loss of lives, there is a need to introduce remedial measures in the construction of such buildings. The 
horizontal bands are helpful in tying the walls together at the junctions and also in preventing the growth of vertical cracks and in-plane shear cracks. However, they may not be adequate in strengthening against out-of-plane flexure, especially for flexure cracks that run horizontally. In this context the Department of Civil Engineering, Indian Institute of Science, has developed the concept of "containment reinforcement' (Raghunath S et al 2000), to contain the flexural tensile cracks from growing. This has also helped in imparting ductility and in absorbing a lot of energy during earthquakes.

\section{References}

Sathish Kumar R 1999 Natural frequencies and mode shapes of brick masonry buildings; $M$. E dissertation report, Dept. of Civil Engg., IISc, Bangalore.

IS 13828: 1993 Improving earthquake resistance of low strength masonry buildings - guidelines, BIS, New Delhi.

Raghunath S, Nanjunda Rao K S and Jagadish K S 2000 Studies on the ductility of brick masonry walls with containment reinforcement; Proc. 6th Int. Seminar on Structural Masonry for Developing Countries, 11th-13th October 2000, IISc, Bangalore. 